\title{
Catalogo del Fondo Stendhal. Biblioteca Primoli, I a cura di Massimo Colesanti
}

\section{Annalisa Bottacin}

\section{(2) OpenEdition}

1 Journals

\section{Edizione digitale}

URL: http://journals.openedition.org/studifrancesi/36357

DOI: 10.4000/studifrancesi.36357

ISSN: 2421-5856

\section{Editore}

Rosenberg \& Sellier

\section{Edizione cartacea}

Data di pubblicazione: 1 juillet 2005

Paginazione: 179-180

ISSN: 0039-2944

\section{Notizia bibliografica digitale}

Annalisa Bottacin, «Catalogo del Fondo Stendhal. Biblioteca Primoli, I a cura di Massimo Colesanti», Studi Francesi [Online], 145 (XLIX | I) | 2005, online dal 30 novembre 2015, consultato il 18 avril 2021. URL: http://journals.openedition.org/studifrancesi/36357 ; DOI: https://doi.org/10.4000/studifrancesi. 36357

Questo documento è stato generato automaticamente il 18 avril 2021.

\section{(c) (1)}

Studi Francesi è distribuita con Licenza Creative Commons Attribuzione - Non commerciale - Non opere derivate 4.0 Internazionale. 


\title{
Catalogo del Fondo Stendhal. Biblioteca Primoli, I a cura di Massimo Colesanti
}

\author{
Annalisa Bottacin
}

\section{NOTIZIA}

Catalogo del Fondo Stendhal. Biblioteca Primoli, I a cura di Massimo COLESANTI, Roma, Edizioni di Storia e Letteratura, «Quaderni di Letteratura Francese, a cura della Fondazione Primoli», n 35, 2002, pp. 361.

1 Nell'accurata introduzione, Massimo Colesanti, Presidente della Fondazione Primoli dal 1991, illustra in modo assai esauriente l'importanza della biblioteca raccolta dal conte Primoli, il cui bisnonno fu Luciano Bonaparte, depositaria di un importante fondo stendhaliano, che il catalogo viene a presentare. In effetti si tratta di una biblioteca molto ricca che solo ultimamente è stata organizzata e recuperata. Vi sono infatti non solo libri appartenuti a Stendhal e studi inerenti al grande scrittore francese, ma edizioni originali di sue opere, uscite postume, oltre a vari altri "settori (letteratura, teatro, viaggiatori, storia, memorie, Roma, Napoleone e i Bonaparte, ecc.), una gran parte delle opere lette, citate, recensite o possedute da Stendhal, in edizioni originali, o comunque antiche o contemporanee, diciamo dal ' 500 al 1842, anzi spesso le stesse edizioni che Stendhal aveva posseduto, o letto, o citato" (p. IX), come ben rileva il curatore. Ancora da segnalare la presenza di altri due fondi che la Biblioteca Primoli ha acquisito negli ultimi cinquant'anni: quello di Jules Baye, depositato presso la Fondazione fin dal 1947 di circa quattromila volumi, e quello di quindicimila volumi, donato nel 1972 da Mario Praz, che fu anche Presidente della Fondazione. Infine per la costituzione, cinque anni or sono, del "Centro di Studi Stendhaliani e Napoleonici", lo stesso Colesanti ha donato parte della sua biblioteca privata. Di qui la necessità di creare un catalogo che da un lato ha consentito di aggiornare l'antico fondo, raccolto dal conte Primoli, che era rimasto fermo alla sua morte avvenuta nel 1927, e di 
integrarlo, con lo scopo di aprire agli studiosi quella che Colesanti definisce la "biblioteca ideale" di Stendhal. Il curatore passa quindi ad illustrare i criteri seguiti per la classificazione dei libri di una biblioteca, in cui il conte Primoli ha riunito incunaboli, cinquecentine, libri preziosi, ricca dunque di testimonianze letterarie italiane ed europee, in particolar modo francesi dal ' 600 all' 800 che si unisce a quella stendhaliana, in cui confluirono doni, lasciti e molti volumi di provenienza della stessa famiglia del conte (parentela romana e francese) e di diretti ascendenti, dai bisnonni, Luciano e Giuseppe Bonaparte, allo zio cardinale Luciano, alla zia Mathilde, fino ad altri napoleonidi romani, come i Ruspoli, i Valenti, i Borghese, ecc. Seguono all"'Introduzione" (pp. VII-XXV), una "Premessa Metodologica" (pp. XXVII-XXIX) e la "Tavola delle Abbreviazioni" (pp. XXXI-XXXIII). L'utile strumento è stato diviso in due sezioni, "L'Opera di Stendhal" (pp. 1-208) con le seguenti sottosezioni: "Edizioni originali appartenute a Stendhal. Appendice I" (pp. 3-10) che facevano parte della biblioteca privata dello scrittore a Roma e a Civitavecchia, di cui Colesanti ripercorre la storia e le caratteristiche tipografiche, e, fatto rilevante, riporta anche in trascrizione tutte le note a margine di Stendhal e di altri, che vengono a integrare e anche a rettificare lezioni precedenti. "Altre opere a lui appartenute. Appendice II", (pp. 43-85); "Altre edizioni originali a) in vita e b) postume" (pp. 86-92); "Altre edizioni a) Fondo antico (1853-1927)” (pp. 93-103); “b) Fondo moderno (1927-2002)” (pp. 104-118); 3) “Traduzioni italiane" (pp. 119-129); "Studi, Saggi, Testimonianze" (pp. 131-191). E ancora "Atti di Convegni e Cataloghi”, (pp. 193- 208); "Riviste e Periodici" (pp. 207-208). La seconda parte ordina dunque accuratamente "La Biblioteca di Stendhal- Autori (Lettere A-E)" (pp. 209-358) con una descrizione bibliografica accurata e pertinente dei volumi, che, in attesa delle nuove uscite, contempla nuovi arricchimenti di indiscutibile prestigio. 